\title{
Calcium Extrusion from Mammalian Photoreceptor Terminals
}

\author{
Catherine W. Morgans,, ${ }^{1,2}$ Oussama El Far, ${ }^{2}$ Amy Berntson,, ${ }^{1}$ Heinz Wässle, ${ }^{1}$ and W. Rowland Taylor ${ }^{1}$ \\ Departments of ${ }^{1}$ Neuroanatomy and ${ }^{2}$ Neurochemistry, Max-Planck-Institute für Hirnforschung, \\ D-60528 Frankfurt, Germany
}

Ribbon synapses of vertebrate photoreceptors constantly release glutamate in darkness. Transmitter release is maintained by a steady influx of calcium through voltage-dependent calcium channels, implying the presence of a mechanism that is able to extrude calcium at an equal rate. The two predominant mechanisms of intracellular calcium extrusion are the plasma membrane calcium ATPase (PMCA) and the $\mathrm{Na}^{+} / \mathrm{Ca}^{2+}$ exchanger. Immunohistochemical staining of retina sections revealed strong immunoreactivity for the PMCA in rod and cone terminals, whereas staining for the $\mathrm{Na}^{+} / \mathrm{Ca}^{2+}$-exchanger was very weak. The PMCA was localized to the plasma membrane along the sides of the photoreceptor terminals and was excluded from the base of the terminals where the active zones are located. The amplitude of a calcium-activated chloride

Neurotransmitter release within the CNS is triggered by pulses of calcium through voltage-gated calcium channels that open in response to depolarization of the plasma membrane. On closure of the channels, the calcium concentration drops and transmitter release declines. Free calcium at the active zone decreases rapidly through diffusion, sequestration by intracellular calcium binding proteins, and ultimately extrusion across the plasma membrane. The rise in calcium in most CNS synaptic terminals is brief because of the short duration of action potential-induced depolarizations (Katz and Miledi, 1967).

In contrast, ribbon synapses, which occur in photoreceptor and bipolar neurons of the retina and in hair cells of the inner ear, are characterized by tonic influx of calcium in response to sustained depolarization (DeVries and Baylor, 1993). Photoreceptors, for example, are constantly depolarized in darkness, their presynaptic calcium channels remain open, and glutamate is continually released (Copenhagen and Jahr, 1989). They respond to light by hyperpolarizing and decreasing the rate of transmitter release. Voltage-dependent calcium channels transduce the hyperpolarization into a decrease in the influx of calcium ions, resulting in a decrease in the intracellular calcium concentration.

The constant influx of calcium into photoreceptors during darkness implies the existence of an efficient calcium extrusion mechanism that exactly balances the rate of calcium entry. This prevents calcium levels from rising in the soma and ensures a rapid decrease in the calcium concentration in the terminal in response to light. By measuring membrane turnover in response

\footnotetext{
Received Sept. 10, 1997; revised Dec. 15, 1997; accepted Dec. 15, 1997.

We are grateful to Dr. Achim Kirsch for expert assistance with the confocal microscopy.

Correspondence should be addressed to Dr. C. W. Morgans, Visual Neurosciences, Division of Neuroscience, John Curtin School of Medical Research, Canberra, ACT, 2600, Australia.

Copyright (C) 1998 Society for Neuroscience $\quad 0270-6474 / 98 / 182467-08 \$ 05.00 / 0$
}

current was used to monitor the intracellular calcium concentration. An upper limit for the time required to remove intracellular free calcium is obtained from two time constants measured for the calcium-activated chloride current tail currents: one of $50 \mathrm{msec}$ and a second of $190 \mathrm{msec}$. Calcium extrusion was inhibited in the absence of intracellular ATP or in the presence of the PMCA inhibitor orthovanadate, but was unaffected by replacement of external $\mathrm{Na}^{+}$with $\mathrm{Li}^{+}$. The data indicate that the PMCA, rather than the $\mathrm{Na}^{+} / \mathrm{Ca}^{2+}$-exchanger, is the predominant mechanism for calcium extrusion from photoreceptor synaptic terminals.

Key words: retina; photoreceptors; calcium extrusion; $\mathrm{Ca}^{2+}$ ATPase; $\mathrm{Na}^{+} / \mathrm{Ca}^{2+}$ exchanger

to the release of caged intracellular calcium, Lagnado and coworkers (1996) and Rieke and Schwartz (1996) found that raising intracellular calcium to $<5 \mu \mathrm{M}$ was sufficient to trigger synaptic vesicle exocytosis from retinal ribbon synapses. These studies suggest that transmitter release might be governed by the average cytosolic calcium concentration rather than calcium microdomains in the vicinity of active channels. If this is true, then the calcium extrusion mechanism could well be an important determinant of the response kinetics of photoreceptor synapses.

In neurons, two mechanisms with somewhat different properties are responsible for extruding calcium ions and returning the calcium concentration to baseline levels (DiPolo and Beauge, 1979; Blaustein, 1988). One is a low-affinity $\mathrm{Na}^{+} / \mathrm{Ca}^{2+}$ exchanger that is linked to the sodium electrochemical gradient. For each calcium pumped out, three sodium ions enter the cell (Reeves and Hale, 1984). The concentration gradients supporting this system are maintained by the $\mathrm{Na}^{+} / \mathrm{K}^{+}$-ATPase. A specialized form of the $\mathrm{Na}^{+} / \mathrm{Ca}^{2+}$-exchanger, which co-transports potassium ions, is responsible for extruding calcium ions from the outer segments of photoreceptors (Lagnado et al., 1988). The other extrusion mechanism is a high-affinity plasma membrane $\mathrm{Ca}^{2+}$-ATPase (PMCA) that can generate large concentration gradients, limited by the free energy change of ATP hydrolysis. One ATP molecule is hydrolyzed for every calcium ion pumped out (Niggli et al., 1981).

The aim of the present study was to determine which of these two mechanisms is responsible for removing calcium from the synaptic terminals of retinal photoreceptors.

\section{MATERIALS AND METHODS}

Antibodies. The mouse monoclonal antibody against the plasma membrane $\mathrm{Ca}^{2+}$-ATPase was purchased from Sigma (Deisenhofen, Germany). The rabbit polyclonal antiserum against the $\mathrm{Na}^{+} / \mathrm{Ca}^{2+}$ exchanger was from Swiss Antibodies. The rabbit polyclonal antibody against synaptobrevin was kindly provided by Dr. M. Takahashi (Mitsubishi Kasei 

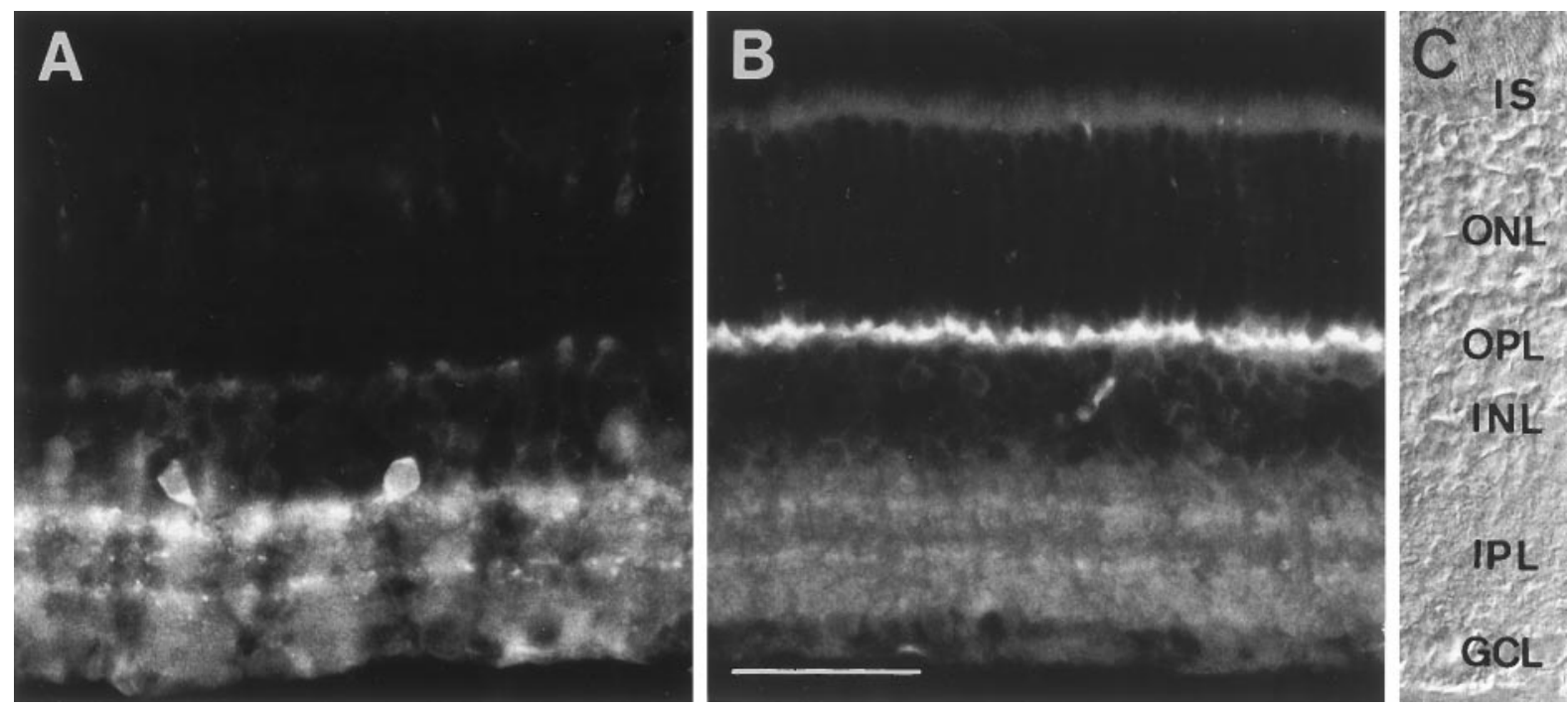

Figure 1. Distribution of $(A)$ the $\mathrm{Na}^{+} / \mathrm{Ca}^{2+}$ exchanger and $(B)$ the PMCA in vertical sections of rat retina detected by immunofluorescence microscopy. $C$, Nomarski micrograph of one of the sections showing the retinal layers. $I S$, Inner segments of photoreceptors; $O P L$, outer plexiform layer; $I N L$, inner nuclear layer; $I P L$, inner plexiform layer; $G C L$, ganglion cell layer. Scale bar, $40 \mu \mathrm{m}$.

Institute of Life Sciences). The following secondary antibodies were used: goat anti-mouse IgG conjugated to CY3 (carboxymethylindocyanine; Dianova, Hamburg, Germany), goat anti-rabbit IgG conjugated to FITC (fluorescein isothiocyanate; Dianova), goat anti-mouse IgG conjugated to FITC (Dianova), and donkey anti-sheep $\operatorname{IgG}$ conjugated to CY3 (Dianova). The syntaxin-3 antibody is described elsewhere (Morgans et al., 1996). The calcium channel antibody D1a was raised against a peptide corresponding a 15 amino acid sequence specific to the $\alpha 1 \mathrm{D}$ subunit of the L-type calcium channel and was the kind gift of Drs. Nicole Martin-Moutot and Michael Seager (Institut National de la Santé et de la Recherche Médicale, Marseille). Polyclonal calcium channel antibodies against peptides unique to either the $\alpha 1 \mathrm{~A}, \alpha 1 \mathrm{~B}$, or $\alpha 1 \mathrm{C}$ subunits were obtained from Alomone Labs (Jerusalem, Israel).

Light microscopic immunocytochemistry. Vertical retina sections were prepared as described previously (Brandstätter et al., 1996b). The sections were incubated for $1 \mathrm{hr}$ in blocking solution [10\% (vol/vol) normal goat serum (NGS), 1\% (wt/vol) bovine serum albumin (BSA), $0.5 \%$ (vol/vol) Triton X-100 in PBS], followed by an overnight incubation in the primary antibody diluted in incubation solution [3\% (vol/vol) NGS, $1 \%$ (wt/vol) BSA, $0.5 \%$ (vol/vol) Triton $\mathrm{X}-100$ in PBS]. The primary antibodies were diluted as follows: PMCA (1:100), $\mathrm{Na}^{+} / \mathrm{Ca}^{2+}$ exchanger (1:1000), synaptobrevin $2(1: 1,000)$, syntaxin $3(1: 50)$, D1a $(1: 1,000), \alpha 1 \mathrm{~A}$ $(1: 60), \alpha 1 \mathrm{~B}(1: 200)$, and $\alpha 1 \mathrm{C}(1: 200)$. After they were washed, the sections were incubated for $1 \mathrm{hr}$ in the appropriate secondary antibody diluted in incubation solution. The secondary antibodies were diluted 1:1000 for CY3 conjugates and 1:50 for FITC conjugates. The sections were washed again and then coverslipped with Mowiol (Höchst, Frankfurt, Germany). Double-labeling experiments were conducted similarly to single-labeling experiments except that both primary antibodies were combined in the overnight incubation. After they were washed, the sections were incubated with a mixture of anti-sheep and anti-mouse secondary antibodies conjugated to CY3 and FITC, respectively, and processed as for single-labeling experiments. Photomicrographs were taken through an Axiophot microscope (Zeiss, Germany). Confocal microscopic images were obtained with a Sarastro 2000 confocal laser scanning microscope system using a $\times 63 / 1.4$ oil immersion objective (Zeiss) as described elsewhere (Brandstätter et al., 1996a).

Immunoblot. Total rat and tree shrew retinae were solubilized in SDS sample buffer and equal quantities of protein were separated by SDSPAGE on a $10 \%$ (wt/vol) acrylamide gel (Laemmli, 1970). The proteins were electrophoretically transferred to nitrocellulose and reacted with the PMCA antibody at a dilution of 1:100 as described previously (Brandstätter et al., 1996b). Immunoreactivity was revealed with an ECL kit (Amersham, Braunschweig, Germany) according to the manufacturer's instructions.

Electrophysiology. Two tree shrews (Tupaia belangeri) were used for these experiments and were handled in accordance with the National
Institutes of Health guidelines for the treatment of experimental animals. The animals were killed by an overdose of sodium pentobarbital injected intraperitoneally. Retinas were isolated, cut into four pieces and maintained in Ames medium (Sigma). A piece of the retina was placed in the recording chamber and superfused with a control solution having the following composition (in $\mathrm{mM}$ ): $\mathrm{NaCl} 120, \mathrm{KCl} 3.1, \mathrm{CaCl}_{2} 1.15, \mathrm{MgCl}_{2}$ $0.6, \mathrm{NaHCO}_{3} 23$, and D-glucose 10 . The $\mathrm{pH}$ of this solution was maintained at 7.4 by equilibration with $95 \% \mathrm{O}_{2}$ and $5 \% \mathrm{CO}_{2}$. The temperature was $23-25^{\circ} \mathrm{C}$. Patch-clamp electrodes were filled with a solution having the following composition (in $\mathrm{mM}$ ): $\mathrm{CsCl} 125, \mathrm{Na}^{+}$-HEPES 5 , $\mathrm{MgCl}_{2}$ 0.6, ATP 1, and GTP 0.1. A calcium buffer was not included, because we wanted to examine the calcium buffering capacity of the surface membrane PMCA. Electrode resistance was 6-10 M $\Omega$, before a whole-cell recording was established. Series resistance was compensated for by at least $75 \%$. Even with series resistance compensation, voltage errors as large as $10 \mathrm{mV}$ might have occurred, but this will not affect the conclusions we draw from the results.

\section{RESULTS}

\section{The PMCA is expressed in photoreceptor terminals}

To determine whether the PMCA or the $\mathrm{Na}^{+} / \mathrm{Ca}^{2+}$ exchanger is likely to play a significant role in calcium extrusion from photoreceptor terminals, vertical sections of rat retina were immunostained with antibodies specific for each of the two proteins (Fig. 1). The $\mathrm{Na}^{+} / \mathrm{Ca}^{2+}$ exchanger antibody showed weak staining throughout presumed cone photoreceptors and no detectable staining of rods (Fig. $1 A$ ). The $\mathrm{Na}^{+} / \mathrm{Ca}^{2+}$ exchanger appeared to be more abundant in the inner retina, where it strongly stained a population of amacrine cell somata. Two immunoreactive bands were visible in the inner plexiform layer (IPL), most probably originating from the stained amacrine cells.

The PMCA immunoreactivity was confined to the synaptic layers of the retina (Fig. $1 B$ ). In contrast to the $\mathrm{Na}^{+} / \mathrm{Ca}^{2+}$ exchanger, the PMCA immunoreactivity was abundant in the outer plexiform layer (OPL), the site of the photoreceptor synapses. The IPL was also stained, although less intensely. The staining in the IPL suggests that bipolar cell terminals also contain the PMCA, albeit at a much lower concentration than the photoreceptor terminals. Within the IPL, two stronger bands of staining could be seen that correspond to the cholinergic bands of starburst amacrine cells (data not shown). The results from the 

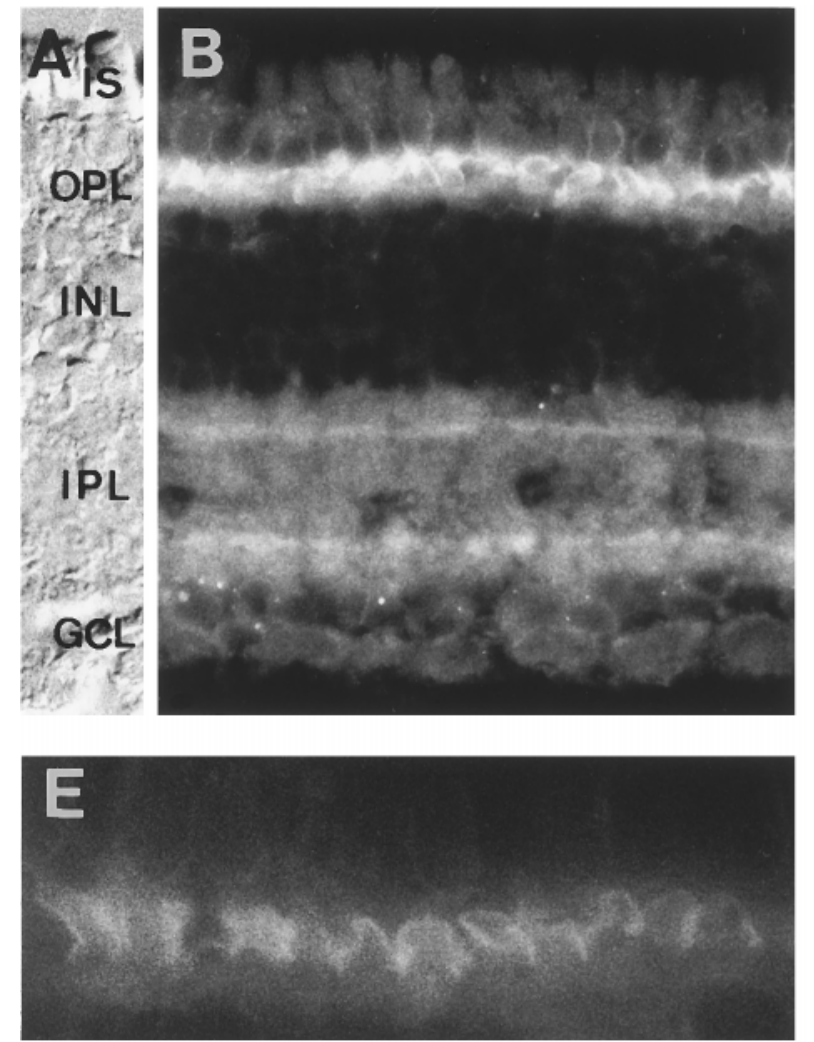
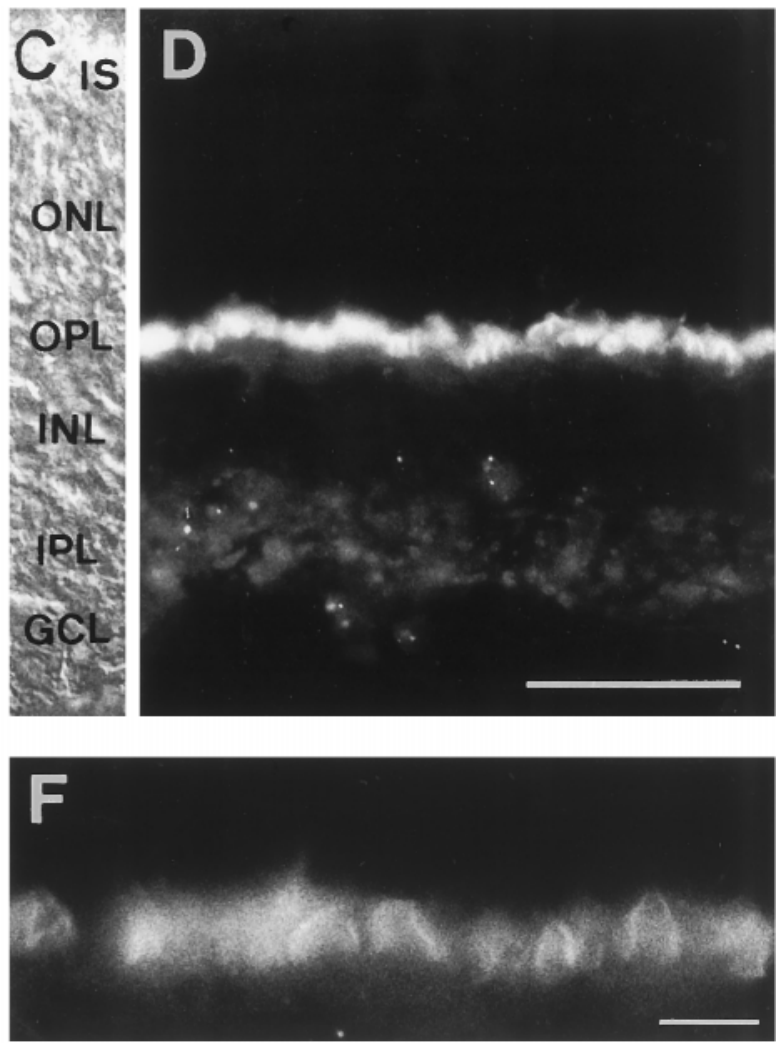

Figure 2. Immunofluorescent staining of the PMCA in vertical sections of tree shrew and gold fish retinae. $A$, Nomarski micrograph of a vertical section of a tree shrew retina. $B$, Immunofluorescent localization of the PMCA in the tree shrew. $C$, Nomarski micrograph of a vertical section of the gold fish retina. $D$, Immunofluorescent localization of the PMCA in gold fish. $E$, High-magnification view of the PMCA staining in the $O P L$ of the tree shrew. $F$, High-magnification view of the PMCA staining in the $O P L$ of gold fish. $I S$, Inner segments of photoreceptors; $O P L$, outer plexiform layer; $I N L$, inner nuclear layer; $I P L$, inner plexiform layer; $G C L$, ganglion cell layer. Scale bar (shown in $D$ for $A-D$ ): $40 \mu \mathrm{m}$; (shown in $F$ for $E, F$ ): $10 \mu \mathrm{m}$.

staining of the rat retina indicate that the PMCA is more abundant than the $\mathrm{Na}^{+} / \mathrm{Ca}^{2+}$ exchanger in the OPL and thus more likely to be important for controlling calcium levels in photoreceptor synaptic terminals.

In addition to rat, the PMCA was immunolocalized in the retinae of the tree shrew and goldfish. The use of these three species allowed a comparison between rod-dominated (rat) and cone-dominated (tree shrew) mammalian retinae and between mammalian and fish retinae. The tree shrew retina was chosen for further studies because the synaptic terminals are large, an advantage for anatomical experiments, and the photoreceptors are relatively easy to patch clamp, facilitating physiological experiments. As in the rat retina, intense PMCA labeling was seen in the OPL of both goldfish and tree shrew retina (Fig. 2B,D). The labeling observed in the IPL of the tree shrew retina was similar to that described above for the rat, including the two brighter bands (Fig. $2 B$ ), which were found to correspond to the cholinergic bands (data not shown). The IPL of the goldfish retina was labeled more weakly, and no stratification was observed (Fig. 2D). Faint but clear labeling was seen in the inner IPL of the goldfish retina over large lobular structures, presumably the giant axon terminals of the ON-bipolar cells. In all three species examined, PMCA staining was restricted to the synaptic layers of the retina and was strongest on the photoreceptor terminals in the OPL.

Inspection at high magnification of the PMCA immunoreactivity in the OPL of both tree shrew and goldfish retinas revealed a striking pattern of staining resembling a row of inverted "V" shapes (Fig. 2E,F). This pattern indicates that the PMCA is restricted to the sides and neck of the photoreceptor terminal but is absent from the base of the terminal, the presumed site of neurotransmitter release.

The specificity of the PMCA antibody was determined with an immunoblot of tree shrew and rat retinae (Fig. 3). An immunoreactive band at $105 \mathrm{kDa}$ was detected in the total retinal proteins of both species, demonstrating that the antibody is highly specific. The antigenic epitope has been mapped to the highly conserved hinge domain of the PMCA polypeptide (Adamo et al., 1992), and the antibody recognizes PMCA isoforms in different tissues and cells (Borke et al., 1990; Kessler et al., 1990; Magocsi and Penniston, 1991; de Talamoni et al., 1993). The size of the band detected in the retina suggests that the PMCA isoform present in retina is PMCA3, which is found primarily in neural tissue (Stauffer et al., 1995). The additional faint bands are likely to be other isoforms and degradation products of the PMCA as have been described by others (Borke et al., 1990; Kessler et al., 1990; de Talamoni et al., 1993).

\section{The PMCA is absent from the active zones of photoreceptor terminals}

To show the proximity of the PMCA to the synaptic active zones in tree shrew photoreceptors, sections were double-labeled with the PMCA antibody and antibodies against the synaptic plasma membrane protein syntaxin 3 and the synaptic vesicle protein synaptobrevin, both of which are associated with synaptic vesicle exocytosis from ribbon synapses (Brandstätter et al., 1996b; Morgans et al., 1996). Syntaxin 3 immunoreactivity (Fig. 4B) was 


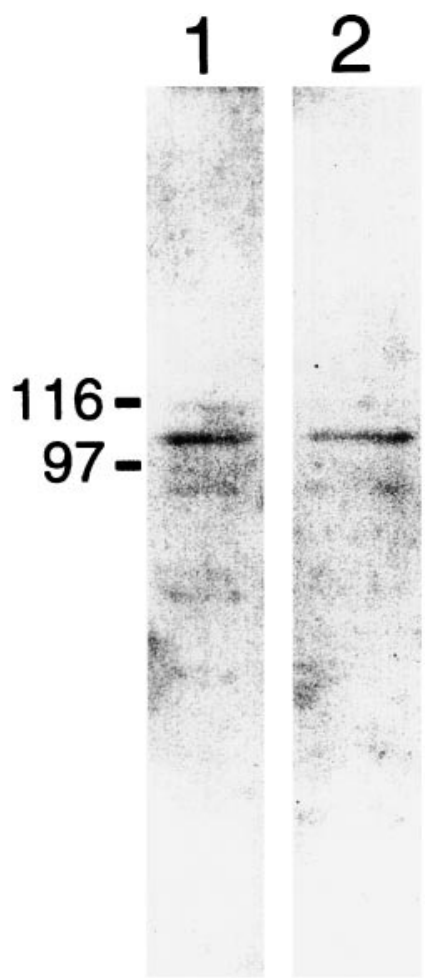

Figure 3. The PMCA antibody recognizes a protein of $105 \mathrm{kDa}$ in both rat (lane 1) and tree shrew (lane 2) retinae. Approximately equal quantities of total protein from rat and tree shrew retinae were separated by SDS-PAGE and immunoblotted with the PMCA antibody. The positions of size markers are indicated on the left.

concentrated at the base of the terminal, marking the region where synaptic vesicles fuse with the plasma membrane. The diff useness of the band of syntaxin 3 immunoreactivity within the synaptic terminals suggests that syntaxin 3 is found on vesicles in addition to the plasma membrane, as has been reported for SNAP-25, a syntaxin 3 binding protein (Brandstätter et al., 1996b). The PMCA was found not to colocalize with syntaxin 3 (Fig. 4A,B), indicating that the PMCA is absent from the active zones of photoreceptor synapses. In contrast to the syntaxin 3 labeling, the synaptobrevin antibody stained the photoreceptors from the base of the terminal to the narrowing just beneath the soma (Fig. 4D), demonstrating that synaptic vesicles entirely fill the photoreceptor terminals but are excluded from the soma. The PMCA immunoreactivity mimics this compartmentalization, enclosing the synaptobrevin staining from the base to the neck of the terminals (Fig. 4C,D).

We compared the localization of the PMCA to that of the photoreceptor presynaptic calcium channels (Fig. 5). The distribution of the PMCA relative to the calcium channels is of particular interest because the arrangement of these proteins is likely to shape the calcium gradient within the photoreceptor terminals. The calcium channels of photoreceptor ribbon synapses have not been identified molecularly; therefore we stained tree shrew retina sections with a panel of calcium channel antibodies against peptide sequences unique to either the $\alpha 1 \mathrm{~A}, \alpha 1 \mathrm{~B}, \alpha 1 \mathrm{C}$, or $\alpha 1 \mathrm{D}$ subunits. The $\alpha 1 \mathrm{~A}$ and $\alpha 1 \mathrm{~B}$ subunits form calcium channels of the P/Q-type and $\mathrm{N}$-type, respectively. Both $\alpha 1 \mathrm{C}$ and $\alpha 1 \mathrm{D}$ calcium channels are sensitive to dihydropyridines and are thus of the L-type. Staining of the photoreceptor terminals was observed with antibodies against both the $\alpha 1 \mathrm{D}$ and $\alpha 1 \mathrm{~B}$ subunits; however, only the $\alpha 1 \mathrm{D}$ subunit appeared to be localized to the plasma membrane, where it was confined to the base of the photoreceptor terminals (Fig. 5). The $\alpha 1 \mathrm{~B}$ immunoreactivity appeared intracellular (data not shown), similar to the synaptobrevin staining (Fig. 4). Consistent with the absence of $\alpha 1 \mathrm{~B}$ from the plasma membrane, $\omega$-conotoxin GVIA, a potent blocker of N-type channels, has been shown not to inhibit photoreceptor calcium currents (Schmitz and Witkovsky, 1997). The significance of the apparent intracellular staining is unclear at present. Antibodies against the $\alpha 1 \mathrm{~A}$ and $\alpha 1 \mathrm{C}$ subunits did not stain tree shrew photoreceptors (data not shown).

Tree shrew retina sections were double-labeled with the PMCA antibody and the antibody specific for the calcium channel $\alpha 1 \mathrm{D}$ subunit (Fig. 5). The two antibodies stained strictly nonoverlapping domains within the photoreceptor terminals. The L-type calcium channels were confined to the base of the photoreceptor terminal, the presumed site of glutamate release. The PMCA is excluded from this membrane domain but is concentrated on the sides and neck of the terminal.

\section{Calcium extrusion is dependent on the PMCA, but not on the $\mathrm{Na}^{+} / \mathrm{Ca}^{2+}$ exchanger}

The identity of the calcium extrusion mechanism was confirmed using an electrophysiological assay. Similar to other species (Maricq and Korenbrot, 1988; Barnes and Hille, 1989; Yagi and Macleish, 1994), tree shrew photoreceptors express a calciumactivated chloride conductance (Taylor and Morgans, 1998), and this was used to monitor the relative intracellular calcium concentration (Roberts, 1993; Tucker and Fettiplace, 1996). Patchclamp electrodes were applied to the inner segments of the photoreceptors. Calcium currents were activated by depolarizing pulses to $-35 \mathrm{mV}$, from a holding potential of $-75 \mathrm{mV}$. When the chloride concentration of the intracellular solution was equimolar with the external solution, large calcium-activated chloride tail currents were observed after return to the holding potential (Figs. $6,7)$. These currents could be suppressed by replacing the extracellular calcium with cobalt (Fig. 6A), which is impermeant through the channels, or with barium, which is permeant but does not activate the chloride current (Taylor and Morgans, 1998). The time course of these currents reflects the rate at which the intracellular calcium concentration returns to resting levels. In 19 cells, the kinetics of the calcium-activated chloride tail currents was measured $\sim 1-2$ min after the whole-cell recording was established. In two cells, the time course was well described by a single exponential function, with time constants of 80 and 90 msec. In the remaining 17 cells a double exponential function was required, with a fast time constant of $50 \pm 25 \mathrm{msec}$ and a slow time constant of $190 \pm 80 \mathrm{msec}$. The amplitude of the fast component was 1.8 times larger than the slow component.

If the photoreceptors contained an isoform of the $\mathrm{Na}^{+} / \mathrm{Ca}^{2+}$ exchanger that was not recognized by the antibody used in this study, it should become evident in the physiological assay. Replacement of the extracellular sodium with lithium is known to potently suppress $\mathrm{Na}^{+} / \mathrm{Ca}^{2+}$ exchange activity (Blaustein and Santiago, 1977), but this substitution had no effect on the rate of decay of the calcium-activated chloride tail currents (Fig. 6A) or on the $\mathrm{Ca}$ Extrusion Index (Fig. $6 B$ ). Similar results were obtained in four cells. This suggests that consistent with the staining, the $\mathrm{Na}^{+} / \mathrm{Ca}^{2+}$ exchanger is functionally absent from the photoreceptor terminals. The $\mathrm{Ca}$ Extrusion Index provided a normalized measure for the efficiency of calcium extrusion $300 \mathrm{msec}$ after repolarization. It was calculated from the tail currents as Ca Extrusion Index $=1-($ tail current amplitude at $300 \mathrm{msec}) /($ peak tail current amplitude). For 

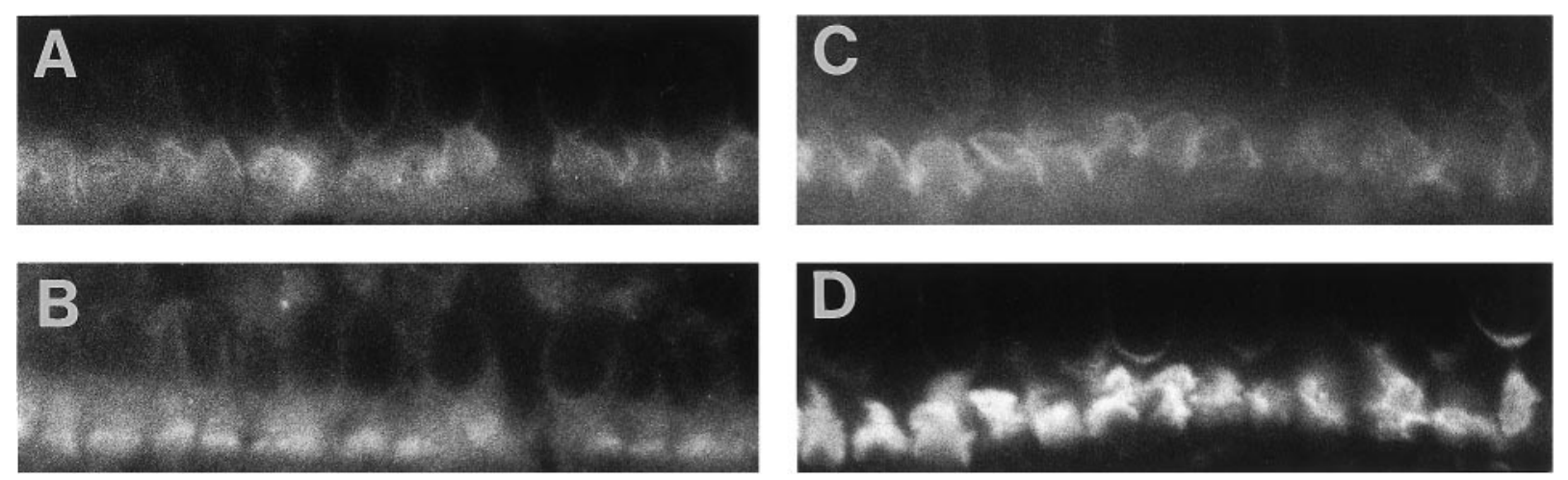

Figure 4. The PMCA is excluded from the sites of neurotransmitter release in photoreceptor terminals. Vertical sections of tree shrew retina were double-immunolabeled either with antibodies against the PMCA and syntaxin 3 ( $A$ and $B$, respectively) or with antibodies against the PMCA and synaptobrevin ( $C$ and $D$, respectively). The scale in $A-D$ is the same as in Figure $2 F$.

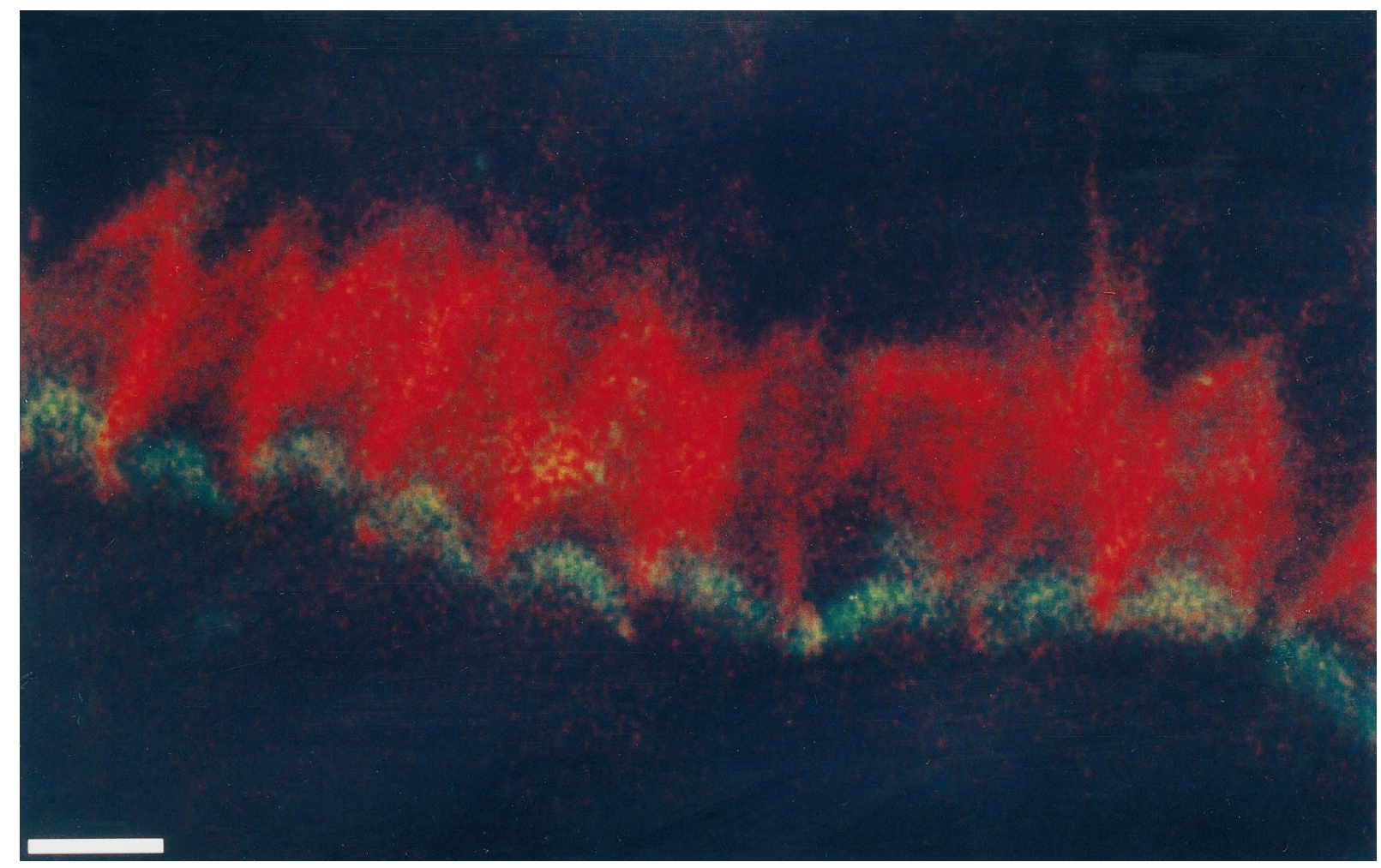

Figure 5. Confocal image of the OPL in a vertical section of tree shrew retina double-labeled for the PMCA (red) and the calcium channel $\alpha 1 \mathrm{D}$ subunit (green). Scale bar, $5 \mu \mathrm{m}$.

efficient extrusion this index will be unity, and for reduced extrusion it will tend toward zero.

Two pieces of evidence consistent with the strong PMCA staining in photoreceptors are shown in Figure 7. First, $1 \mathrm{~mm}$ $\mathrm{Na}^{+}$-orthovanadate, which is known to block the PMCA but not the endoplasmic reticulum $\mathrm{Ca}^{2+}$-ATPase in other systems (Carafoli, 1992), potently increased the duration and magnitude of the calcium-activated chloride tail currents (Fig. 7), even in the presence of $1 \mathrm{mM} \mathrm{Mg}^{2+}$-ATP. Second, the time course of decay of the calcium-activated chloride tail currents was much slower when $\mathrm{Mg}^{2+}$-ATP was not included in the intracellular solution (Fig. $7 B$, open triangles). This is consistent with the extrusion of calcium being dependent on ATPase activity, because the intracellular ATP will be lost rapidly during the course of the recording, leading to suppression of the PMCA activity. After suppression of the PMCA activity, the tail currents lasted for many seconds, rather than $\sim 0.10 \mathrm{sec}$ as was the case when the PMCA was active.

\section{DISCUSSION}

Photoreceptor terminals and other ribbon synapses are able to support tonic neurotransmitter release, but to do so they are faced with the challenge of maintaining a high calcium concentration at the active zone while keeping calcium levels low elsewhere in the cell. Of the two known means of calcium extrusion, the PMCA was shown by immunofluorescence to be abundant in photoreceptor terminals, whereas the $\mathrm{Na}^{+} / \mathrm{Ca}^{2+}$ exchanger was very weakly detected in cones and not at all in rods. The PMCA antibody intensely stained the OPL of both the rod-dominated retina of the 
A.

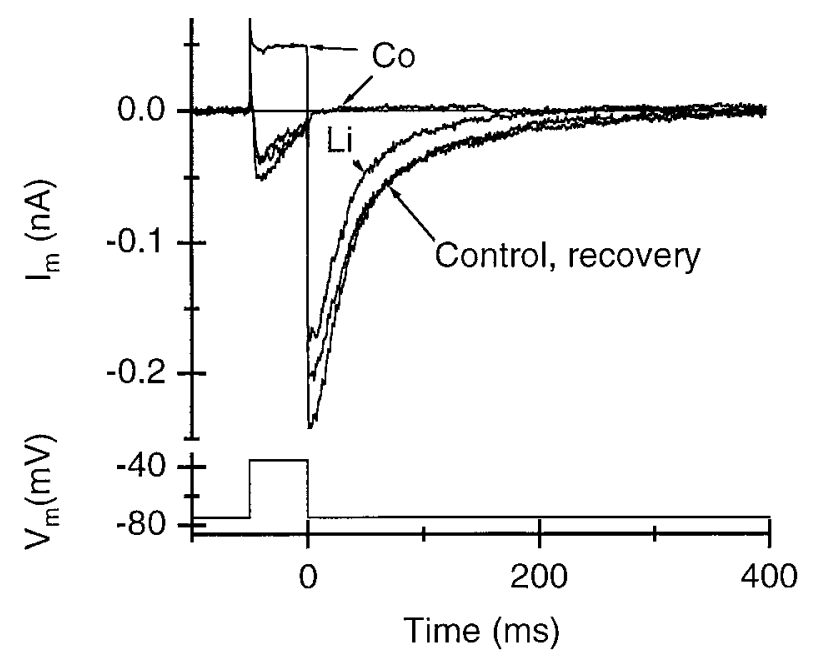

B.

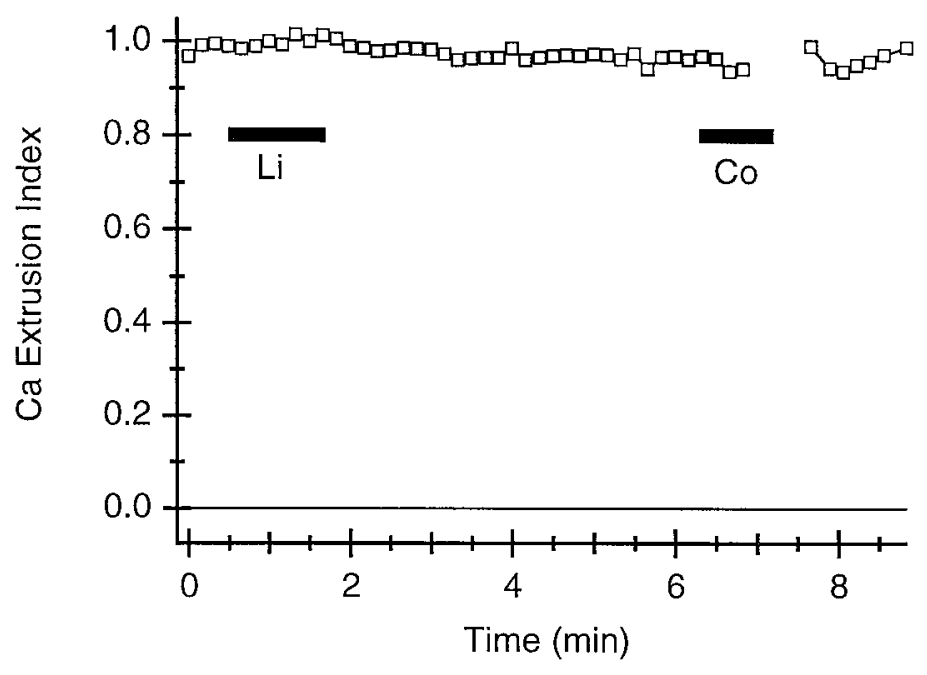

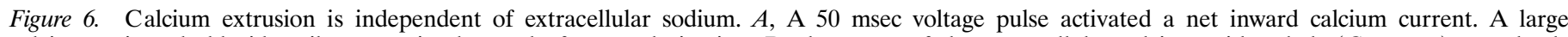

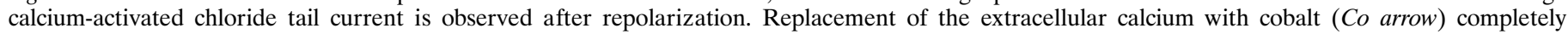

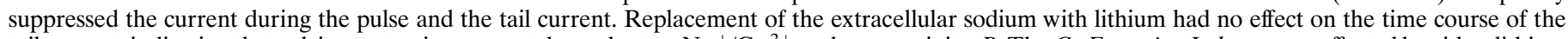

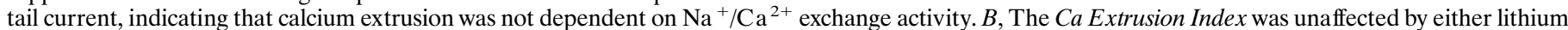

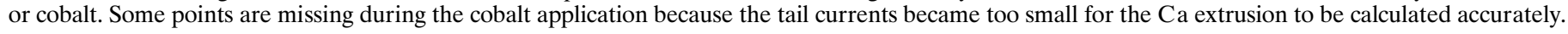

rat and the cone-dominated retina of the tree shrew, suggesting that the PMCA is present in both rod and cone terminals. Using a calcium-activated chloride current as an indicator of the intracellular calcium concentration, we showed that inhibition of the PMCA dramatically prolonged the chloride tail currents in tree shrew photoreceptors. Inhibition of the $\mathrm{Na}^{+} / \mathrm{Ca}^{2+}$ exchanger, on the other hand, was without effect. The immunolocalization of the PMCA coupled with the physiological data strongly suggest that PMCA activity is critical for rapidly reducing the intracellular calcium concentration in photoreceptor terminals.

Double-labeling of retina sections with antibodies against synaptic markers and the PMCA demonstrated that the active zone is spatially distinct from the sites of calcium efflux within the photoreceptor terminals. Both syntaxin 3 and the calcium channel $\alpha 1 \mathrm{D}$ subunit are localized to the base of the synaptic terminal, the presumed site of transmitter release, whereas the PMCA is concentrated along the sides and neck of each terminal. The precise segregation of the PMCA and the active zone markers raises the question of how photoreceptors are able to establish and maintain these functionally and spatially distinct plasma membrane domains within their synaptic terminals. Interactions between membrane proteins and the submembrane cytoskeleton or extracellular matrix are likely to be involved.

Of a panel of antibodies recognizing different calcium channel $\alpha 1$ subunits, only the $\alpha 1 \mathrm{D}$ antibody appeared to stain the photoreceptor plasma membrane. This is consistent with findings from electrophysiological studies indicating the presence of L-type calcium channels in ribbon synapses of photoreceptors (Rieke and Schwartz, 1994; Wilkinson and Barnes, 1996; Schmitz and Witkovsky, 1997), bipolar cells (Heidelberger and Matthews, 1992; Tachibana et al., 1993; Pan and Lipton, 1995), and inner ear hair cells (Art and Fettiplace, 1987). The relative distribution of the $\alpha 1 \mathrm{D}$ calcium channels and the PMCA indicates that the sites of calcium influx and efflux within a photoreceptor synaptic terminal might be spatially segregated, possibly giving rise to the formation of a standing calcium ion gradient across the terminal (Fig. 8). This would be an attractive mechanism to ensure high calcium levels required to sustain continuous glutamate release from the terminal while preventing the calcium concentration in the soma from rising and activating other cellular processes. Although none of the other calcium channel antibodies used in this study appeared to stain photoreceptor plasma membranes in the tree shrew, the presence of other calcium channels in the photoreceptor terminals cannot be ruled out. Intracellular calcium channels are also a possibility. Indeed, an intracellular staining pattern was observed in the photoreceptor terminals with an antibody against the $\alpha 1 \mathrm{~B}$ subunit of $\mathrm{N}$-type calcium channels. The $\alpha 1 \mathrm{~B}$ immunoreactivity may be caused by cross-reactivity with $\mathrm{IP}_{3}$ or $\mathrm{Ca}^{2+}$-gated intracellular calcium channels and warrants further investigation.

The activity of the PMCA could influence the light response of bipolar cells, the neurons postsynaptic to photoreceptors, particularly if glutamate release from photoreceptors is controlled by the average calcium concentration in the terminals rather than the high calcium concentrations reached only within microdomains around open channels. By measuring capacitance changes in response to photolysis of caged calcium, Rieke and Schwartz (1996) found that a high rate of synaptic vesicle exocytosis in rod terminals is maintained by a $\mathrm{Ca}^{2+}$ concentration of $2-4 \mu \mathrm{m}$, which is the average cytoplasmic $\mathrm{Ca}^{2+}$ concentration at the dark resting potential. Bipolar cells, the other ribbon synapse-forming neurons of the retina, have been shown to have two modes of glutamate release: a transient mode that responds to calcium concentrations in the range of $100 \mu \mathrm{m}$ (Heidelberger et al., 1994; von Gersdorff and Matthews, 1994), and a continuous mode supported by a rise in the average calcium concentration of the terminal to $1 \mu \mathrm{m}$ or less (Lagnado et al., 1996).

If the rate of transmitter release is determined by the average intracellular calcium concentration in photoreceptors, then the rate at which the intracellular calcium concentration changes could limit the response kinetics of the synaptic transfer. We have shown that suppression of calcium extrusion greatly prolonged calcium-activated chloride tail currents, indicating that intracel- 
A.

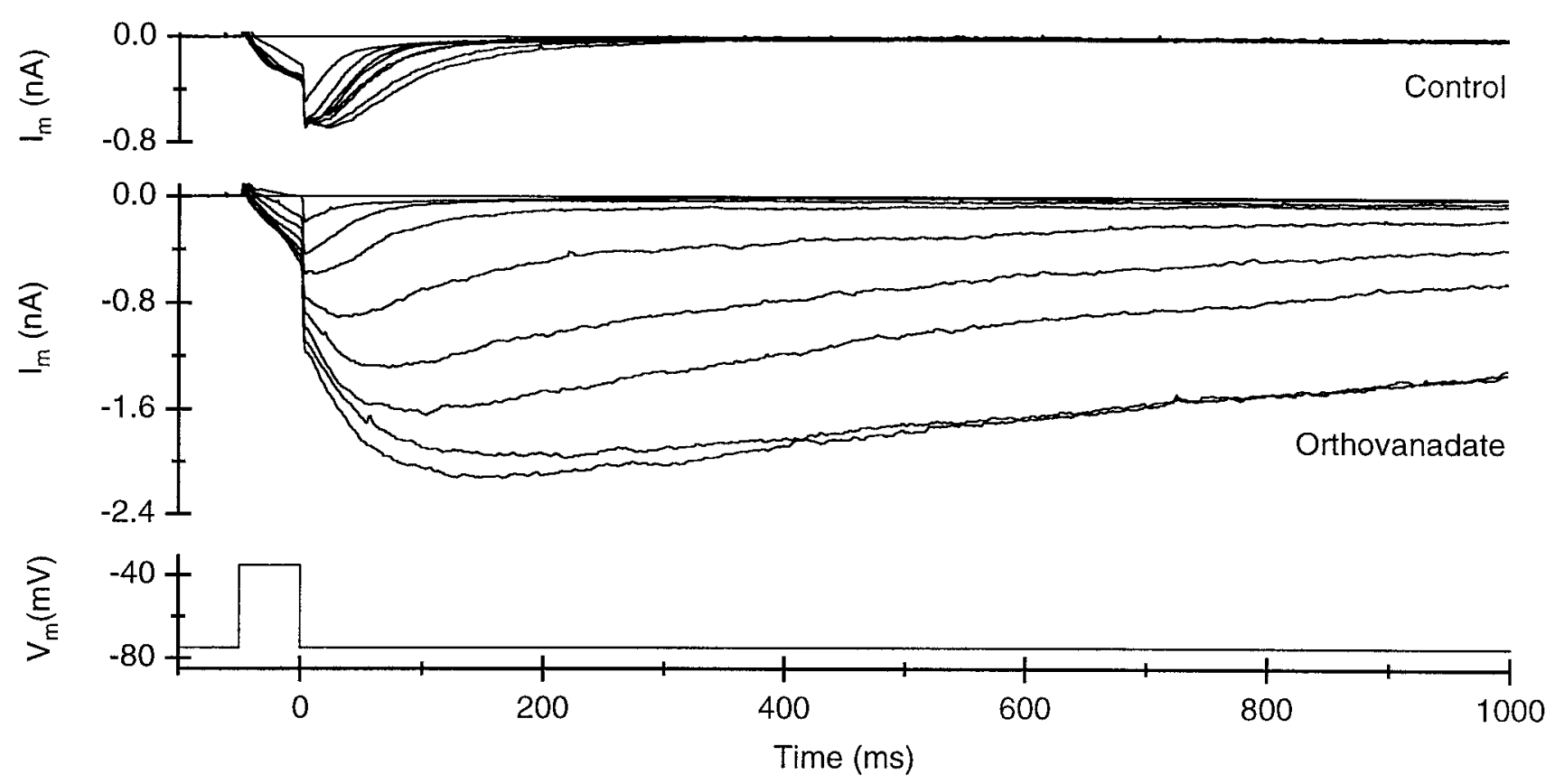

B.

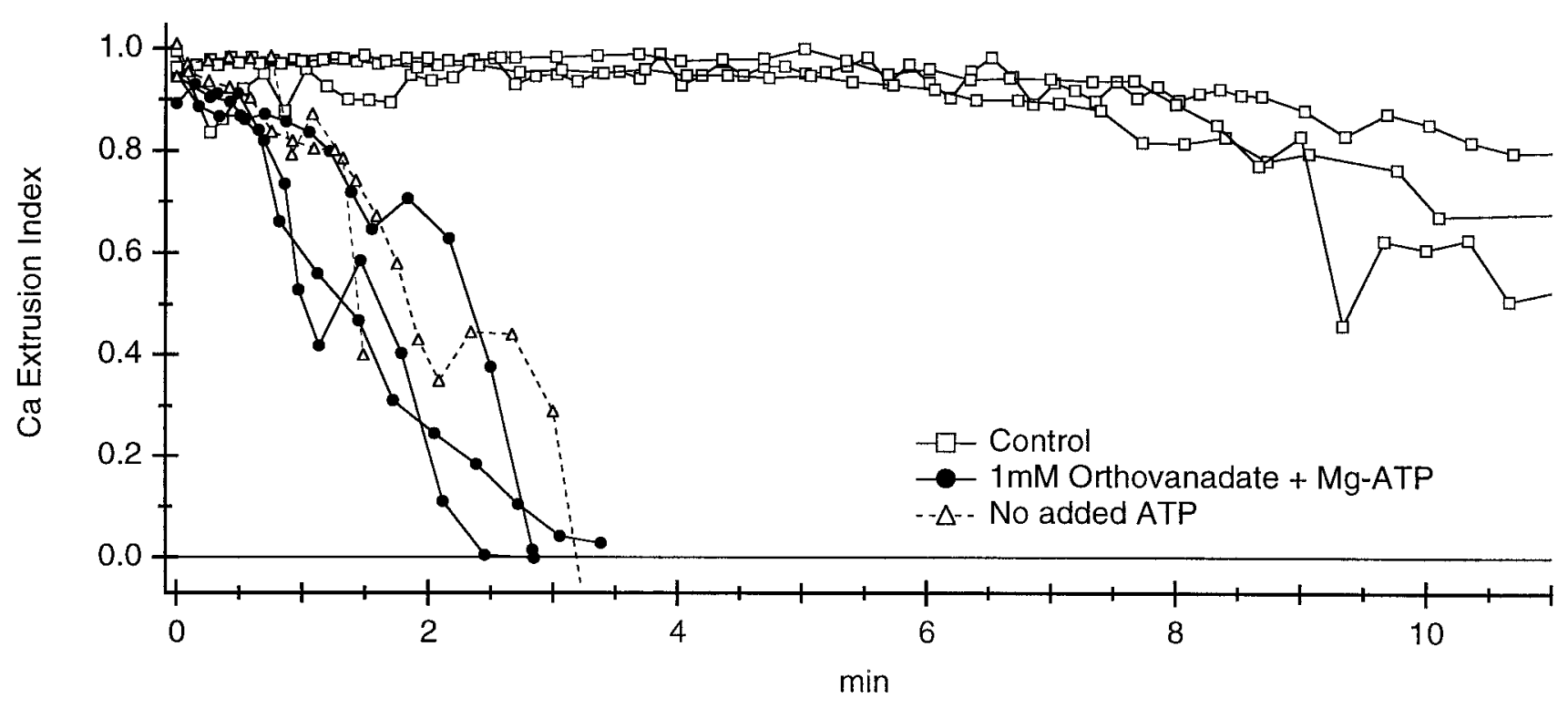

Figure 7. PMCA activity is crucial for efficient calcium extrusion from photoreceptors. $A$, The time course of the calcium-activated chloride tail currents remained fairly stable during a 4 min period (top records), but rapidly became large and prolonged during a similar period when $1 \mathrm{~mm} \mathrm{Na}^{+}$-orthovanadate was included in the intracellular solution (bottom records). $B$, The open symbols accurately show that in the control cells $\left(1 \mathrm{mM} \mathrm{Mg}{ }^{2+}-\mathrm{ATP}^{-}\right.$intracellular, 3 cells) the $\mathrm{Ca}$ Extrusion Index remained stable for up to $10 \mathrm{~min}$. The closed circles show the effects of including $1 \mathrm{~mm}^{\mathrm{Na}}{ }^{+}$-orthovanadate in the intracellular solution ( 3 cells). A similar effect was observed when $\mathrm{Mg}^{2+}$-ATP was omitted from the intracellular solution (open triangles; 2 cells).

lular calcium remained elevated. What do the tail currents under control conditions tell us about intracellular calcium concentration? It is tempting to suppose that they track the intracellular free calcium, but alternatively they may simply reflect the deactivation kinetics of the underlying chloride channels. Unfortunately little is known about the kinetics or calcium sensitivity of the calcium-activated chloride current in neurons, and so we do not know how rapidly the current changes in response to fluctu- ations in the calcium concentration. Because we saw progressive prolongation of the tail currents, we can say, however, that the tail currents provide an upper limit for the time constant of calcium extrusion. This means that the calcium concentration dropped as fast as, and not slower than, the 50 and $190 \mathrm{msec}$ time constants recorded. In this context it is intriguing to note that the fast time constant is similar to that recorded for light-on responses in rat bipolar cells (W. Taylor, unpublished results). This is consistent 


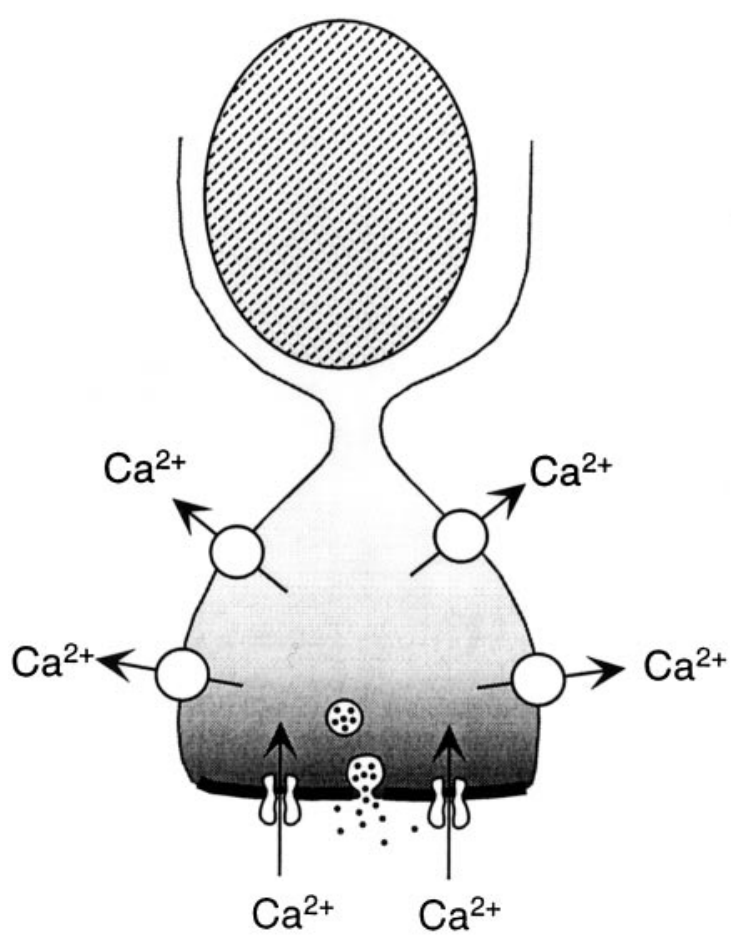

Figure 8. Diagram of the synaptic terminal of a tree shrew cone. Sites of calcium influx and extrusion are segregated, possibly giving rise to a standing calcium gradient in darkness when the cell is depolarized. As depicted by a fusing synaptic vesicle, glutamate release occurs from the base of the terminal where the calcium channels are located and the calcium concentration is highest.

with the notion that the rate at which transmitter release from photoreceptors can be shut off is determined by the rate at which the intracellular calcium concentration can be lowered. If this is true, then the PMCA, by determining the rate of calcium extrusion, could well exert a significant influence over the kinetics of synaptic transfer. In other systems the activity of the PMCA is subject to modulation by direct interaction with calmodulin and by phosphorylation by protein kinases A and C (Carafoli, 1992). Modulation of the photoreceptor PMCA could add a further level of control over glutamate release and thus synaptic transfer from these neurons.

\section{REFERENCES}

Adamo H, Caride A, Penniston J (1992) Use of expression mutants and monoclonal antibodies to map the erythrocyte $\mathrm{Ca}^{2+}$ pump. J Biol Chem 267:14244-9.

Art JJ, Fettiplace R (1987) Variation of membrane properties in hair cells isolated from the turtle cochlea. J Physiol (Lond) 385:207-242.

Barnes S, Hille B (1989) Ionic channels of the inner segment of tiger salamander cone photoreceptors. J Gen Physiol 94:719-743.

Blaustein MP (1988) Calcium transport and buffering in neurons. Trends Neurosci 11:438-443.

Blaustein MP, Santiago EM (1977) Effects of internal and external cations and of ATP on sodium-calcium and calcium-calcium exchange in squid axons. Biophys J 20:79-111.

Borke J, Caride A, Verma A, Penniston J, Kumar R (1990) Cellular and segmental distribution of $\mathrm{Ca} 2(+)$-pump epitopes in rat intestine. Pflügers Arch 417:120-122.

Brandstätter JH, Löhrke S, Morgans CW, Wässle H (1996a) Distributions of two homologous synaptic vesicle proteins, synaptoporin and synaptophysin, in the mammalian retina. J Comp Neurol 370:1-10.

Brandstätter JH, Wässle H, Betz H, Morgans CW (1996b) The plasma membrane protein SNAP-25, but not syntaxin, is present at photoreceptor and bipolar cell synapses in the rat retina. Eur J Neurosci 8:823-828.

Carafoli E (1992) The $\mathrm{Ca}^{2+}$ pump of the plasma membrane. J Biol Chem 267:2115-2118.
Copenhagen DR, Jahr CE (1989) Release of endogenous excitatory amino acids from turtle photoreceptors. Nature 341:356-359.

de Talamoni N, Smith C, Wasserman R, Beltramino C, Fullmer C, Penniston J (1993) Immunocytochemical localization of the plasma membrane calcium pump, calbindin-D28k, and parvalbumin in Purkinje cells of avian and mammalian cerebellum. Proc Natl Acad Sci USA 90:11949-11953.

DeVries S, Baylor DA (1993) Synaptic circuitry of the retina and olfactory bulb. Cell 72:139-149.

DiPolo R, Beauge L (1979) Physiological role of ATP-driven calcium pump in squid axon. Nature 278:271-273.

Heidelberger R, Matthews G (1992) Calcium influx and calcium current in single synaptic terminals of goldfish retinal bipolar neurons. J Physiol (Lond) 447:235-256.

Heidelberger R, Heinemann C, Neher E, Matthews G (1994) Calcium dependence of the rate of exocytosis in a synaptic terminal. Nature 371:513-515.

Katz B, Miledi R (1967) The timing of calcium action during neuromuscular transmission. J Physiol (Lond) 189:535-544.

Kessler F, Bennardini F, Bachs O, Serratosa J, James P, Caride A, Gazzotti P, Penniston J, Carafoli E (1990) Partial purification and characterization of the $\mathrm{Ca} 2(+)$-pumping ATPase of the liver plasma membrane. J Biol Chem 265:16012-16019.

Laemmli UK (1970) Cleavage of structural proteins during the assembly of the head of bacteriophage T4. Nature 227:680-685.

Lagnado L, Cervetto L, McNaughton PA (1988) Ion transport by the $\mathrm{Na}-\mathrm{Ca}$ exchange in isolated rod outer segments. Proc Natl Acad Sci USA 85:4548-4552.

Lagnado L, Gomis A, Job C (1996) Continuous vesicle cycling in the synaptic terminal of retinal bipolar cells. Neuron 17:957-967.

Magocsi M, Penniston J (1991) Oxytocin pretreatment of pregnant rat uterus inhibits $\mathrm{Ca} 2+$ uptake in plasma membrane and sarcoplasmic reticulum. Biochim Biophys Acta 1063:7-14.

Maricq A, Korenbrot J (1988) Calcium and calcium-dependent chloride currents generate action potentials in solitary cone photoreceptors. Neuron 1:503-515.

Morgans C, Brandstätter J, Kellerman J, Betz H, Wässle H (1996) A SNARE complex containing syntaxin 3 is present in ribbon synapses of the retina. J Neurosci 16:6713-6721.

Niggli V, Adunyah E, Penniston J, Carafoli E (1981) Purified (Ca2+$\mathrm{Mg} 2+$ )-ATPase of the erythrocyte membrane. Reconstitution and effect of calmodulin and phospholipids. J Biol Chem 256:395-401.

Pan ZH, Lipton SA (1995) Multiple GABA receptor subtypes mediate inhibition of calcium influx at rat retinal bipolar cell terminals. J Neurosci 15:2668-2679.

Reeves JP, Hale CC (1984) The stoichiometry of the cardiac sodiumcalcium exchange system. J Biol Chem 259:7733-7739.

Rieke F, Schwartz E (1994) A cGMP-gated current can control exocytosis at cone synapses. Neuron 13:863-873.

Rieke F, Schwartz E (1996) Asynchronous transmitter release: control of exocytosis and endocytosis at the salamander rod synapse. J Physiol (Lond) 493:1-8.

Roberts WM (1993) Spatial calcium buffering in saccular hair cells. Nature 363:74-76.

Schmitz Y, Witkovsky P (1997) Dependence of photoreceptor glutamate release on a dihydropyridine-sensitive calcium channel. Neuroscience 78:1209-1216.

Stauffer TP, Guerini D, Carafoli E (1995) Tissue distribution of the four gene products of the plasma membrane $\mathrm{Ca}^{2+}$ pump. J Biol Chem 270:12184-12190.

Tachibana M, Okada T, Arimura T, Kobayashi K, Piccolino M (1993) Dihydropyridine-sensitive calcium current mediates neurotransmitter release from bipolar cells of the goldfish retina. J Neurosci 13:2898-2909.

Taylor WR, Morgans CW (1998) Localization and properties of voltagegated calcium channels in cone photoreceptors of Tupaia belangeri. Vis Neurosci, in press.

Tucker T, Fettiplace R (1996) Monitoring calcium in turtle hair cells with a calcium-activated potassium channel. J Physiol (Lond) 494:613-626.

von Gersdorff H, Matthews G (1994) Dynamics of synaptic vesicle fusion and membrane retrieval in synaptic terminals. Nature 367:735-739.

Wilkinson M, Barnes S (1996) The dihydropyridine-sensitive calcium channel subtype in cone photoreceptors. J Gen Physiol 107:621-630.

Yagi T, Macleish P (1994) Ionic conductances of monkey solitary cone inner segments. J Neurophysiol 71:656-665. 